\title{
LUT
}

University

\section{Applicability of a field portable X-ray fluorescence for analyzing elemental concentration of waste samples}

Havukainen Jouni, Hiltunen Jaana, Puro Liisa, Horttanainen Mika

This is a Final draft

version of a publication

published by Elsevier

in Waste Management

DOI: $10.1016 /$ j.wasman.2018.10.039

Copyright of the original publication: (c) 2018 Elsevier Ltd.

Please cite the publication as follows:

Havukainen, Jouni., Hiltunen, Jaana., Puro, Liisa., Horttanainen, Mika. (2019). Applicability of a field portable X-ray fluorescence for analyzing elemental concentration of waste samples. Waste Management, 83, ss. 6-13. DOI. 10.1016/j.wasman.2018.10.039.

This is a parallel published version of an original publication. This version can differ from the original published article. 


\title{
Applicability of a field portable X-ray fluorescence for analyzing elemental concentration of waste samples
}

\author{
Jouni Havukainen ${ }^{\mathrm{a},{ }^{*}}$, Jaana Hiltunen a, Liisa Puro ${ }^{\mathrm{b}}$, Mika Horttanainen ${ }^{\text {a }}$ \\ a Lappeenranta University of Technology, Sustainability Science. P.O. Box 20, FI- \\ 53851, Lappeenranta, Finland \\ ${ }^{\mathrm{b}}$ Lappeenranta University of Technology, Chemical Engineering. P.O. Box 20, FI- \\ 53851, Lappeenranta, Finland \\ *Corresponding author: Jouni Havukainen, Sustainability Science, \\ Lappeenranta University of Technology, P.O. Box 20, 53851 \\ Lappeenranta, Finland \\ Email: jouni.havukainen@lut.fi
}

\begin{abstract}
Determining the chemical properties of waste is crucial to ensure the most effective utilization of waste. The standard laboratory measurements can produce accurate results, but analysis is labor- and time-consuming. The variety of elements that field portable X-ray fluorescence spectrometry (FPXRF) can detect from selected waste materials was studied, including how the results compared with those of inductively coupled plasma mass spectrometry (ICP-MS) measurements. The selected materials were fine fraction reject from solid recovered fuel production, fly ash, biowaste, and compost. Based on the results, FPXRF is reported to be best suited for waste samples, such as ash and compost, because of their physical properties, as follows: not too moist, quite small particle size, and not too heterogeneous. The results obtained from FPXRF showed the lowest relative standard deviation for ash material. The analysis of the limits of agreement between FPXRF and ICP-MS showed that FPXRF was mainly suitable for qualitative assessment. Furthermore, regression analysis showed a linear correlation between FPXRF and ICP-MS results for calcium and zinc in the selected materials. Keeping the limitations in mind, FPXRF could be used for qualitative analysis in waste treatment processes, such as first quality control of waste materials.
\end{abstract}

Keywords: field portable x-ray fluorescence spectrometry, inductively coupled plasma mass spectrometry, elemental analysis, waste 


\section{Introduction}

Waste recovery is becoming increasingly important as natural resources are being depleted. Information on elements, such as potentially toxic trace elements, and on concentrations of waste is required for the determination of suitable utilization methods or safe final disposal locations. For example, to dispose fine fraction reject from solid recovered fuel (SRF) production to a landfill for non-hazardous waste in Finland, it is mandatory to find out if the concentrations of certain substances, such as $\mathrm{As}, \mathrm{Cd}, \mathrm{Hg}, \mathrm{Cu}$ and $\mathrm{Pb}$, exceed the limits in regulation $(333 / 221)$.

Currently, the properties of waste are measured in laboratories with analytical methods, such as inductively coupled plasma mass spectrometry (ICP-MS) and atomic absorption spectroscopy (AAS). While these laboratory analyses are accurate, there are some problems related to them (Weindorf et al., 2012). Due to the heterogeneous nature of waste, large amounts of samples are needed to obtain representative results. However, the number of samples is limited when ICP-MS and AAS methods are used because they are timeconsuming, costly, and require experienced technicians (Kilbride et al., 2006). Another problem involves sample preparation, which may be prone to sample contamination, resulting in inaccurate results (Hou et al., 2004). Based on the few laboratory tests, a decision can be made on the utilization or the disposal of a large quantity of materials.

Measuring element concentrations online with sufficient accuracy could provide significant benefits to enable the utilization of materials. This would allow directing fraction, which is most probably suitable for utilization to a pile that is different from fraction that is unsuitable for utilization. For example, in deciding the treatment for ash, online measurement could guide a conveyor so that ash requiring heavy metal removal (Havukainen et al., 2016) would be separated (and dumped on a different pile) from ash that has concentrations safely below the limits and requires less treatment. Field portable X-ray fluorescence spectrometry (FPXRF) could be one solution to tackle the challenges posed by laboratory analysis. FPXRF is a fast, nondestructive technique that can provide qualitative or quantitative elemental analysis of any kind of sample material (Hou et al., 2004; Kalnicky and Singhvi, 2001). One advantage of FPXRF is that the technique requires no or only little sample preparation, which enables rapid nondestructive analysis.

The review by Gałuszka et al. (2015) showed that there has been development in portable instruments, including FPXRF, which has been used for example in rapid on-site screening of soil samples (Miller et al., 2013) and measuring lead in dust wipe samples (Sterling et al., 2000). Miller et al. (2013) used portable XRF for measuring mercury contamination of soil from industrial complex and found that the sample heterogeneity causes complexity for the measurements while Sterling et al (2000) found that portable XRF can be used for rapid onsite evaluation of dust wipes. Kilbride et al. (2006) used two types of FPXRF to measure soil samples and compared metal concentrations using FPXRF against ICP-optical emission spectrometry (OES) analysis. The X-ray tube instrument successfully measured $\mathrm{Fe}$ and $\mathrm{Pb}$ concentrations, whereas the dual source XRF instrument was able to measure $\mathrm{Fe}, \mathrm{Cu}, \mathrm{Pb}, \mathrm{Zn}$, Cd, and Mn concentrations (Kilbride et al., 2006). Similarly, Radu and Diamond (2009) 
studied heavy metal contamination of soils in mining facilities. $\mathrm{Pb}, \mathrm{As}, \mathrm{Cu}$, and $\mathrm{Zn}$ concentrations were analyzed by using FPXRF and AAS. FPXRF demonstrated an excellent correlation with the AAS method. Gutiérrez-Ginés et al. (2013) studied heavy metal concentrations in soil and plant samples by using FPXRF. The samples were collected from abandoned mine sites and sealed landfills in Spain. The results showed a high quality of the measurements of $\mathrm{As}, \mathrm{Ca}, \mathrm{Cd}, \mathrm{Cr}, \mathrm{Cu}, \mathrm{Fe}, \mathrm{K}, \mathrm{Mn}, \mathrm{Ni}, \mathrm{Pb}, \mathrm{Rb}, \mathrm{Sr}, \mathrm{Ti}$, and $\mathrm{Zn}$ concentrations. Additionally, the FPXRF analysis was found to save on costs, materials, and time when compared with accurate laboratory analysis (Gutiérrez-Ginés et al., 2013).

One of the recent applications of FPXRF is the identification of $\mathrm{As}, \mathrm{Cu}, \mathrm{Cr}$ in wood waste (Block et al., 2007; Hasan et al., 2011). Burlakovs et al. (2015) found that FPXRF could be used for fast, semi-quantitative evaluation of certain metallic elements in samples from landfill mining tests. McWhirt et al. (2012) were able to measure $\mathrm{Ca}, \mathrm{Cr}, \mathrm{Cu}, \mathrm{Fe}, \mathrm{K}, \mathrm{Mn}, \mathrm{P}$, and $\mathrm{Zn}$ concentrations from dried compost samples by using FPXRF, whereas As detection was found to be unsuccessful. Similarly, Weindorf et al. (2008) concluded that FPXRF was effective in detecting concentrations of $\mathrm{Ni}, \mathrm{Cu}, \mathrm{Zn}, \mathrm{Se}, \mathrm{Mo}$, and $\mathrm{Pb}$ but was unable to measure $\mathrm{Hg}, \mathrm{Cd}$, or As.

Only a few studies have been conducted using FPXRF to characterize solid wastes, such as ash, compost, and fine fraction reject from SRF production. In fact, this present study is one of the first to examine fine fraction reject from SRF production by using FPXRF. The objective of this study is to find out which elements can be measured with FPXRF and how these results compare with those of laboratory measurements using ICP-MS. The aim is to preliminarily estimate whether FPXRF would be suitable for online waste measurements to aid in faster decision making and better utilization of waste. The research focuses on measuring solid wastes and waste processing products or rejects that have relatively small particle sizes.

\section{Materials and methods}

\subsection{Sample details and preparation}

Four different waste materials were selected to evaluate the suitability of FPXRF measurements of different types of waste products, including fine fraction reject, fly ash, biowaste, and compost. The waste materials were mixed homogeneously, and three samples of each material were placed in 0.5-liter zip-lock bags. The fine fraction reject came from the manufacturing of SRF, which consisted of commercial and industrial waste. The fine fraction reject is the underflow from the star screen, which is located after primary shredding and the belt magnet but before the air classifier. The particle size ranges between 0 and $15 \mathrm{~mm}$. To compare the particle size's effect on the measurement results, a part of the fine fraction was ground to a 2-mm size by mechanical milling. The fly ash came from the Finnish power plant using bark and logging residues as fuel. The biowaste and the compost came from the same anaerobic digestion and composting plant. The plant processes separately collect biowaste, sewage sludge, and garden waste. The digestion residue is converted into a compost product, which can be used as a fertilizer. Both moist and dried samples of biowaste and compost were 
used in FPXRF measurements to compare the impact of moisture in FPXRF measurements. Moisture measurements were separately performed for each of the three zip-lock bags. ICPMS measurements were performed for the ground fine fraction reject, ash, and dried compost. A schematic overview of the treatment of the samples before the analysis can be seen from supplementary data Figure S1.

\subsection{Field portable X-ray fluorescence (FPXRF) analysis}

The Niton XL3t 900s XRF analyzer (Thermo Scientific Inc.) with an X-ray tube operated at $50 \mathrm{keV}$ and a geometrically optimized large drift detector (GOLDD) was used in this study. The analyzer is able to measure a range of elements from magnesium to uranium. The standard configuration mode, known as the mining mode, was used in the measurements. The mining mode was selected to measure the waste samples because it could be assumed that these were the most similar to heterogeneous soil samples. More information about the analyzer can be found from the supplementary material presented in Table S1, and the limits of detection (LOD) are shown in Table S2. The waste samples were analyzed through the ziplock bags. Each of the three zip-lock bags was scanned eight times, four points from both sides through the bag, meaning that one waste material was scanned a total of 24 times. The analysis time for one scan was 80 seconds, meaning that the total analysis time for one ziplock bag was a little less than 11 minutes. The measuring time of 80 seconds was selected since a longer measurement time did not reduce significantly the standard deviation of the measurement.

\subsection{Laboratory analysis using inductively coupled plasma mass spectrometry (ICP-MS)}

The comparative elemental analysis was performed by using ICP-MS (Agilent Technologies 7900) (SFS-EN ISO 16968). The LOD and the limit of quantification of ICP-MS are shown in the supplementary material (Table S3). Elemental analysis by ICP-MS requires liquid samples; thus, solid samples have to be converted into liquid form by microwave digestion. Before the digestion, the samples were pretreated by drying them in an oven for 12 hours at $105^{\circ} \mathrm{C}$ and subsequently ground in a mortar to obtain smaller particle sizes. Four 0.1 -g samples were prepared from each of the three zip-lock bags, meaning that one waste material was analyzed 12 times. For the digestion, the 0.1-g samples were weighed in a test tube, and 4 $\mathrm{ml}$ of concentrated nitric acid $\left(\mathrm{HNO}_{3}\right.$ at $\left.67 \%\right)$ and $1 \mathrm{ml}$ of concentrated hydrochloric acid ( $\mathrm{HCl}$ at $37 \%)$ were added. The digestion was accomplished by using an UltraWAVE Single Reaction Chamber Microwave Digestion (Milestone Inc.). After the digestion, the samples were diluted and analyzed by using the ICP-MS analyzer. The concentration of potassium was not measured with ICP-MS. In addition, the ICP-MS method was unable to determine $\mathrm{Cl}$ concentration; therefore, $\mathrm{Cl}$ was measured by ion exchange-chromatography (IC). Chloride was analyzed according to the standard SFS-EN ISO 10304-2 with the Thermo Fisher ICS 1100 equipment. The used column consisted of IonPac AG22 (4 x 50mm + AS22 (4 x $250 \mathrm{~mm}$ ) and eluent $4.5 \mathrm{mM} \mathrm{Na} 2 \mathrm{CO}_{3}+1.4 \mathrm{mM} \mathrm{NaHCO}_{3}$. Water extraction was done for the samples before the IC analysis. 


\subsection{Data analysis}

The element concentration and the precision of analysis were reported by FPXRF on an individual element basis for each scan. The mean value, standard deviation (SD), relative standard deviation (RSD), and minimum and maximum values for each waste sample were determined. The mean value and the SD were calculated for each sample on the basis of 24 measurements. Used to evaluate a method's precision, RSD is the ratio of the SD and the mean concentration of an element (EPA, 2007). For FPXRF measurement data to be considered precise, the RSD should not exceed 20\% (EPA, 2007).

The Bland-Altman plot analysis with limits of agreement (LA) (Martin Bland and Altman, 1986) was used to assess the agreement between the FPXRF and the ICP-MS measurements. The average values of the measured element concentrations of the three zip-lock bags per material were used in the analysis. The range of the LA was compared with the range of the values obtained from the ICP-MS measurement to estimate the agreement. The LA values are calculated based on the mean difference between the measurements and the SD of the differences, using Equation (1) (Ranganathan et al., 2017):

$\mathrm{LA}=$ mean difference $\pm 1.96 \times \mathrm{SD}$ of differences

A linear regression analysis was used to obtain prediction models and model performance statistics. The analysis was used to investigate the relationship between the element concentrations measured by using ICP-MS and FPXRF. The data were log transformed to satisfy the assumptions of the linear regression and to standardize variance (EPA, 2007). The coefficient of determination $\left(\mathrm{R}^{2}\right)$ was used to describe the accuracy of fit. The closer $\mathrm{R}^{2}$ is to 1 , the better the model is able to explain the linear relationship between the measurement methods. The coefficient of determination and the RSD are used to characterize the data generated by FPXRF. Table 1 shows the criteria for characterizing the data quality.

Table 1. Criteria for characterizing data quality (EPA, 2007; Kilbride et al., 2006).

\begin{tabular}{lll}
\hline \multirow{2}{*}{ Data quality level } & \multicolumn{2}{l}{ Statistical requirement } \\
& $\mathbf{R}^{\mathbf{2}}$ & RSD \\
\hline Definitive & $0.9-1$ & $\leq 10 \%$ \\
Quantitative & $0.7-0.9$ & $<20 \%$ \\
Qualitative & $<0.7$ & $>20 \%$ \\
\hline $\mathrm{R}^{2}=$ coefficient of determination, $\mathrm{RSD}=$ relative standard deviation
\end{tabular}

\section{Results and discussion}

\subsection{The results of FPXRF}

Tables 2 and 3 summarize the element concentration ranges of the SRF waste samples measured by FPXRF. According to the EPA, the FPXRF measurement data can be characterized as quantitative when the RSD is less than $20 \%$, with the exception of Cr, whose RSD should be less than $30 \%$ (EPA, 2007). The coarse fine fraction reject performed poorly since the RSD was less than $20 \%$ only for $\mathrm{Cd}$ and $\mathrm{Cl}$. The grinding of the fine fraction reject 
reduced the $\mathrm{RSD}$ of $\mathrm{Pb}, \mathrm{Zn}, \mathrm{Cu}, \mathrm{Fe}, \mathrm{Ca}, \mathrm{K}, \mathrm{Cd}$, and $\mathrm{V}$ but increased the $\mathrm{RSD}$ of $\mathrm{Cr}$ and $\mathrm{Cl}$. These findings indicate that the grinding of samples can produce more accurate results from the RSD perspective. Additionally, after the grinding, As and Mn could be detected from the sample, which were not detected in the coarse fine fraction reject. In terms of RSD, the concentrations of $\mathrm{Zn}, \mathrm{Fe}, \mathrm{Ca}, \mathrm{K}, \mathrm{Cd}$, and $\mathrm{V}$ in the ground fine fraction reject were quantitative, according to EPA standards. Ash, which is already much more homogeneous than fine fraction reject, performed much better; almost all the results were quantitative, and the concentrations of $\mathrm{Pb}, \mathrm{As}, \mathrm{Ca}, \mathrm{K}$, and $\mathrm{Cl}$ could even be considered definitive ( $\mathrm{RSD} \leq 10 \%)$.

Table 2. Element concentrations $(\mathrm{mg} / \mathrm{kg})$ determined by FPXRF in SRF fine fraction and ash samples.

\begin{tabular}{llllllllllllll}
\hline Sample & $\mathbf{P b}$ & $\mathbf{A s}$ & $\mathbf{Z n}$ & $\mathbf{C u}$ & $\mathbf{F e}$ & $\mathbf{M n}$ & $\mathbf{C r}$ & $\mathbf{C a}$ & $\mathbf{K}$ & $\mathbf{C d}$ & $\mathbf{C l}$ & $\mathbf{V}$ \\
\hline \multicolumn{2}{l}{ Coarse fine fraction reject } & & & & & & & & & \\
Mean & 36 & n.d. & 566 & 659 & 7214 & n.d. & 200 & 27824 & 2771 & 21 & 2821 & 102 \\
Min & 15 & & 243 & 132 & 3757 & & 91 & 16419 & 1672 & 14 & 1828 & 53 \\
Max & 156 & & 1378 & 3793 & 12184 & & 565 & 53545 & 4226 & 26 & 3944 & 221 \\
SD & 30 & & 282 & 873 & 2170 & & 124 & 8688 & 622 & 4 & 539 & 46 \\
RSD & $84 \%$ & & $50 \%$ & $132 \%$ & $30 \%$ & & $62 \%$ & $31 \%$ & $22 \%$ & $17 \%$ & $19 \%$ & $45 \%$ \\
Ground fine fraction & reject & & & & & & & & & \\
Mean & 62 & 17 & 756 & 521 & 9176 & 226 & 202 & 38825 & 2858 & 19 & 3693 & 142 \\
Min & 36 & 11 & 598 & 347 & 6890 & 175 & 105 & 34055 & 2438 & 14 & 2685 & 109 \\
Max & 163 & 27 & 966 & 1311 & 11502 & 282 & 768 & 45486 & 3369 & 24 & 11280 & 205 \\
SD & 29 & 5 & 116 & 216 & 1377 & 38 & 131 & 2774 & 261 & 2 & 1713 & 24 \\
RSD & $48 \%$ & $32 \%$ & $15 \%$ & $42 \%$ & $15 \%$ & $17 \%$ & $65 \%$ & $7 \%$ & $9 \%$ & $13 \%$ & $46 \%$ & $17 \%$ \\
Ash & & & & & & & & & & & & \\
Mean & 357 & 39 & 2138 & 711 & 62882 & 4552 & 333 & 94625 & 19172 & n.d. & 3541 & 306 \\
Min & 294 & 33 & 1703 & 533 & 54529 & 3651 & 277 & 72001 & 17663 & & 2744 & 144 \\
Max & 410 & 46 & 2686 & 1124 & 77134 & 6037 & 443 & 109933 & 20986 & & 4142 & 375 \\
SD & 31 & 5 & 259 & 160 & 5451 & 558 & 43 & 8613 & 750 & & 355 & 64 \\
RSD & $9 \%$ & $14 \%$ & $12 \%$ & $23 \%$ & $9 \%$ & $12 \%$ & $13 \%$ & $9 \%$ & $4 \%$ & & $10 \%$ & $21 \%$ \\
\hline
\end{tabular}

n.d. $=$ not detected, $\mathrm{Min}=$ minimum, Max $=$ maximum, $\mathrm{SD}=$ standard deviation, $\mathrm{RSD}=$ relative standard deviation

Table 3 summarizes the element concentrations of moist and dry compost and biowaste samples on a dry matter basis. The moisture content was on average $60 \%$ for biowaste and $36 \%$ for compost. The element concentrations of the moist and the dry samples on a dry matter basis were closer to each other for compost samples than for biowaste samples. The moist compost samples had 3-10\% lower values for $\mathrm{Zn}, \mathrm{Fe}$, and $\mathrm{K}$ and 3-10\% higher values for $\mathrm{Ca}$ and $\mathrm{Cl}$. The moist biowaste samples had 13-37\% lower values for $\mathrm{Zn}, \mathrm{Fe}$, and $\mathrm{K}$ and $21-33 \%$ higher values for $\mathrm{Ca}$ and $\mathrm{Cl}$. These results seemed to indicate that the higher moisture content of biowaste resulted in a more significant difference between moist and dry samples. Moisture also seemed to affect the detection of some elements in moist compost and biowaste since after the drying, concentrations of $\mathrm{Mn}$ in compost and concentrations of $\mathrm{Cu}$, $\mathrm{Cr}, \mathrm{Mo}$, and $\mathrm{V}$ in biowaste were detected, which were not detected in the moist samples. For compost, the element concentrations on a dry matter basis were quantitative for $\mathrm{Zn}, \mathrm{Cu}, \mathrm{Fe}, \mathrm{K}$, $\mathrm{Cl}$, and $\mathrm{V}$ for both moist and dry samples and for $\mathrm{Ca}$ and $\mathrm{Mn}$ in the dry samples. The concentrations were qualitative for $\mathrm{Cr}$ and $\mathrm{Ca}$ for the moist samples. The RSD values were 
higher for biowaste, but $\mathrm{Ca}, \mathrm{K}, \mathrm{Cd}$, and $\mathrm{Cl}$ concentrations in the moist samples and $\mathrm{K}, \mathrm{Cl}, \mathrm{Mo}$, and $\mathrm{V}$ concentrations in the dry samples could still be considered quantitative. On the other hand, $\mathrm{Zn}$ concentration in the moist sample and $\mathrm{Zn}, \mathrm{Cu}, \mathrm{Fe}, \mathrm{Cr}, \mathrm{Ca}$, and $\mathrm{Cd}$ concentrations in the dry sample could only be considered qualitative. More detailed information about the element concentrations of grinded fine fraction, ash and compost can be found in the supplementary data (Tables S4, S5, and S6).

Table 3. Element concentrations $(\mathrm{mg} / \mathrm{kg})$ on a dry matter basis determined by FPXRF in dry and moist compost and biowaste samples.

\begin{tabular}{|c|c|c|c|c|c|c|c|c|c|c|c|c|}
\hline Sample & $\mathbf{P b}$ & As & $\mathbf{Z n}$ & $\mathbf{C u}$ & $\mathrm{Fe}$ & Mn & $\mathrm{Cr}$ & $\mathbf{C a}$ & $\mathbf{K}$ & Cd & $\mathrm{Cl}$ & $\mathbf{V}$ \\
\hline \multicolumn{13}{|c|}{ Compost, moist } \\
\hline Mean & n.d. & n.d. & 313 & 131 & 72891 & n.d. & 171 & 21088 & 13415 & n.d. & 5965 & 136 \\
\hline Min & & & 229 & 105 & 52767 & & 118 & 15950 & 10106 & & 5393 & 96 \\
\hline Max & & & 355 & 171 & 95066 & & 282 & 82195 & 14623 & & 7244 & 160 \\
\hline SD & & & 31 & 18 & 8043 & & 36 & 13963 & 896 & & 382 & 16 \\
\hline RSD & & & 313 & 131 & 72891 & n.d. & 171 & 21088 & 13415 & n.d. & 5965 & 136 \\
\hline \multicolumn{13}{|c|}{ Compost, dry } \\
\hline Mean & n.d. & n.d. & 322 & 153 & 73517 & 231 & 169 & 19049 & 14640 & n.d. & 5801 & 140 \\
\hline Min & & & 236 & 117 & 52773 & 140 & 97 & 16149 & 13238 & & 4524 & 89 \\
\hline Max & & & 371 & 197 & 83051 & 327 & 280 & 22173 & 15838 & & 7544 & 187 \\
\hline SD & & & 33 & 24 & 7176 & 43 & 39 & 1680 & 851 & & 732 & 23 \\
\hline RSD & & & 322 & 153 & 73517 & 231 & 169 & 19049 & 14640 & n.d. & 5801 & 140 \\
\hline \multicolumn{13}{|c|}{ Biowaste, moist } \\
\hline Mean & n.d. & n.d. & 74 & n.d. & 12419 & n.d. & n.d. & 14861 & 7587 & 31 & 5067 & n.d. \\
\hline Min & & & 38 & & 7704 & & & 10064 & 6257 & 22 & 3883 & \\
\hline Max & & & 123 & & 15905 & & & 18708 & 10263 & 43 & 7771 & \\
\hline SD & & & 22 & & 2473 & & & 2339 & 876 & 5 & 1036 & \\
\hline RSD & & & $30 \%$ & & $20 \%$ & & & $16 \%$ & $12 \%$ & $15 \%$ & $20 \%$ & \\
\hline \multicolumn{13}{|c|}{ Biowaste, dry } \\
\hline Mean & n.d. & n.d. & 116 & 53 & 14148 & n.d. & 88 & 11100 & 8872 & 17 & 4172 & 47 \\
\hline Min & & & 75 & 35 & 10235 & & 64 & 8918 & 6160 & 12 & 3145 & 38 \\
\hline Max & & & 164 & 98 & 22365 & & 100 & 17891 & 11242 & 25 & 5052 & 61 \\
\hline SD & & & 24 & 16 & 3009 & & 20 & 2331 & 969 & 4 & 451 & 8 \\
\hline RSD & & & $21 \%$ & $31 \%$ & $21 \%$ & & $23 \%$ & $21 \%$ & $11 \%$ & $21 \%$ & $11 \%$ & $17 \%$ \\
\hline
\end{tabular}

\subsection{The results of ICP-MS and ion exchange-chromatography}

The elemental concentrations of SRF ground fine fraction, compost, and ash were analyzed with ICP-MS and IC (for $\mathrm{Cl}$ ). The linear regression between FPXRF and ICP-MS measurements could only be performed for $\mathrm{Ca}, \mathrm{Cr}, \mathrm{Fe}, \mathrm{Cu}, \mathrm{Zn}$, and $\mathrm{V}$ and between FPXRF and IC for $\mathrm{Cl}$ because the FPXRF was unable to measure other elements across the entire range of these waste materials (ground fine fraction reject, ash, and compost). Table 4 summarizes the concentrations of these elements and of $\mathrm{Pb}$ and $\mathrm{As}$, where comparisons between FPXRF and ICP-MS could be made for ash and ground fine fraction reject, as well as the concentrations of $\mathrm{Cd}$, where a comparison could be made for ground fine fraction reject. 
More detailed information about the element concentrations measured by ICP-MS can be found in the supplementary data (Tables S7, S8, and S9). The RSD values of element concentrations in ash were lower than in ground fine fraction reject and compost, highlighting the more homogeneous nature of ash compared with the other two materials. The RSD values of element concentrations in the ash samples were below $10 \%$ for almost all elements (Table 4) and below $20 \%$ for the rest of the elements. The compost samples performed relatively well, and besides As and $\mathrm{Ca}$, the concentrations of all the other elements were below $20 \%$. Fine fraction reject could be considered the most heterogeneous of all tested materials since its RSD was below $20 \%$ only for $\mathrm{As}, \mathrm{Ca}, \mathrm{Cl}$, and V.

Table 4. Element concentrations (mg/kg) determined by ICP-MS and IC $(\mathrm{Cl})$.

\begin{tabular}{|c|c|c|c|c|c|c|c|c|c|c|c|}
\hline Sample & $\mathbf{P b}$ & As & Zn & $\mathrm{Cu}$ & $\mathbf{F e}$ & Mn & $\mathrm{Cr}$ & $\mathbf{C a}$ & Cd & Cl & $\mathbf{V}$ \\
\hline \multicolumn{12}{|c|}{ Ground fine fraction reject } \\
\hline Mean & 115 & 12 & 948 & 2520 & 14008 & 582 & 418 & 49337 & 3 & 1684 & 20 \\
\hline Min & 54 & 9 & 513 & 305 & 7305 & 414 & 162 & 42265 & 1 & 1660 & 15 \\
\hline Max & 495 & 16 & 2935 & 12017 & 48075 & 747 & 2252 & 59740 & 22 & 1702 & 26 \\
\hline SD & 121 & 2 & 729 & 3560 & 11280 & 107 & 586 & 5031 & 6 & 21 & 3 \\
\hline RSD & $105 \%$ & $17 \%$ & $77 \%$ & $141 \%$ & $81 \%$ & $18 \%$ & $140 \%$ & $10 \%$ & $222 \%$ & $1 \%$ & $16 \%$ \\
\hline \multicolumn{12}{|l|}{ Ash } \\
\hline Mean & 274 & 29 & 1490 & 413 & 42753 & 3446 & 221 & 85375 & 3 & 1709 & 38 \\
\hline Min & 232 & 27 & 1361 & 361 & 40721 & 3222 & 206 & 81206 & 3 & 1677 & 36 \\
\hline Max & 350 & 30 & 1652 & 515 & 45617 & 3703 & 252 & 90245 & 3 & 1743 & 41 \\
\hline SD & 32 & 1 & 87 & 53 & 1501 & 131 & 15 & 3231 & 0 & 33 & 2 \\
\hline RSD & $12 \%$ & $2 \%$ & $6 \%$ & $13 \%$ & $4 \%$ & $4 \%$ & $7 \%$ & $4 \%$ & $3 \%$ & $2 \%$ & $4 \%$ \\
\hline \multicolumn{12}{|c|}{ Compost } \\
\hline Mean & 17 & 6 & 408 & 178 & 82722 & 527 & 46 & 33662 & 0 & 6062 & 44 \\
\hline Min & 10 & 3 & 260 & 111 & 54089 & 350 & 28 & 18212 & 0 & 5759 & 28 \\
\hline Max & 24 & 9 & 457 & 208 & 95380 & 598 & 52 & 60592 & 1 & 6574 & 49 \\
\hline SD & 3 & 1 & 54 & 26 & 11225 & 66 & 6 & 11436 & 0 & 446 & 6 \\
\hline RSD & $19 \%$ & $24 \%$ & $13 \%$ & $15 \%$ & $14 \%$ & $12 \%$ & $14 \%$ & $34 \%$ & $16 \%$ & $7 \%$ & $13 \%$ \\
\hline
\end{tabular}

\subsection{Box plot analysis}

The results of the ICP-MS and the FPXRF measurements for ground fine fraction reject are summarized in the box plots presented in Figure 1. The boxes represent the first and the third quartiles, and the line in each box signifies the median. The vertical lines above and below the boxes extend to the highest and the lowest data points, respectively, within 1.5 times the interquartile range (IQR), while the values outside this range are presented as outliers. The results of the ICP-MS measurements for ground fine fraction reject revealed the homogeneous nature of the fine fraction reject because besides $\mathrm{Mn}$ and $\mathrm{V}$, all the other elements had outliers, some of which considerably differed from the average, such as $\mathrm{Cd}$, whose outlier was eight times larger than the average. This outcome was also evident in the RSD values of the ICP-MS measurements (Table 3), which were highest for ground fine fraction reject. The FPXRF measurements were closest to those of ICP-MS for $\mathrm{Ca}$ and $\mathrm{Zn}$, with the averages 
being 20\% lower than for ICP-MS. The largest difference was for $\mathrm{V}$ and $\mathrm{Cd}$, where FPXRF indicated $600 \%$ higher average concentrations.

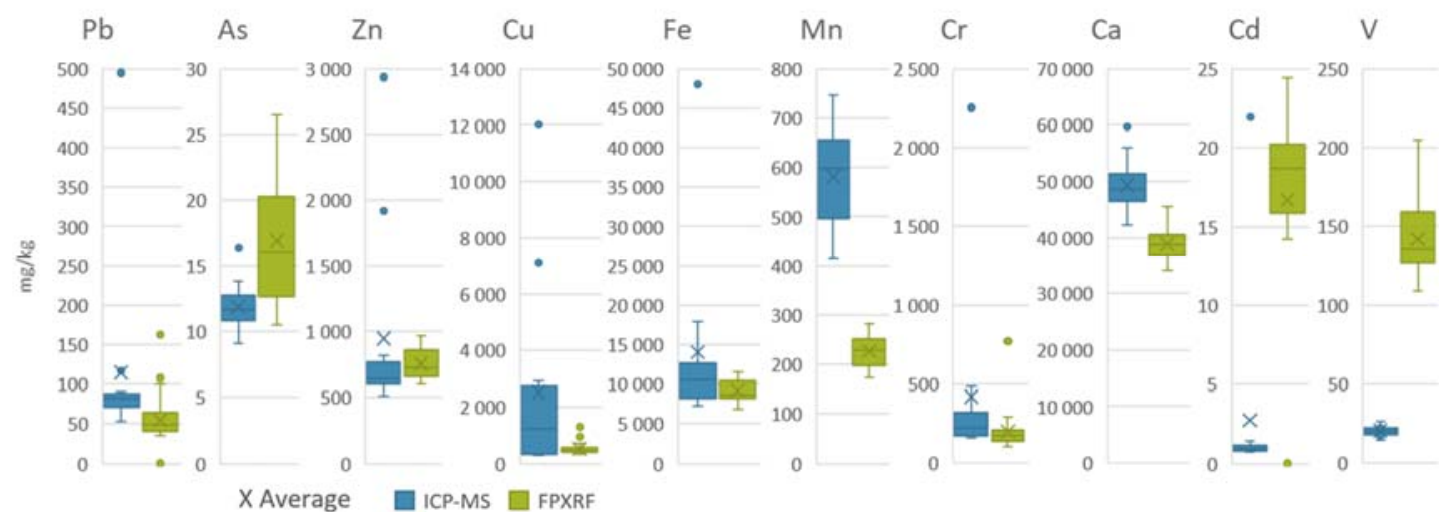

Figure 1. Box plots of ICP-MS and FPXRF measurements for ground fine fraction reject (the dots represent outliers).

The results for the fine fraction reject can be compared to those of the study by Burlakovs et al. (2015), who used FPXRF to measure the reject from landfill mining. Their study found that $\mathrm{Ca}$ and $\mathrm{Fe}$ concentrations could be reliably measured by FPXRF. Moreover, $\mathrm{Pb}, \mathrm{Zn}, \mathrm{Cu}$, $\mathrm{Mn}$, and $\mathrm{Cr}$ could be screened by FPXRF, but the use of laboratory methods might be necessary to verify the results (Burlakovs et al., 2015). Their study's findings are supported by those of this present study concerning the screening of $\mathrm{Pb}, \mathrm{Zn}, \mathrm{Cu}, \mathrm{Mn}$, and $\mathrm{Cr}$ values despite the higher variations among the element concentrations. One reason for this difference could be the pretreatment of the samples in the study of Burlakovs et al. (2015).

Figure 2 presents the box plot analysis of the ash measurements using ICP-MS and FPXRF. The measurements by ICP-MS showed lower variations compared with ground fine fraction reject, and there were also not as many outliers. On the other hand, the FPXRF measurements had more outliers than in the case of the ground fine fraction reject. The FPXRF measurements resulted in higher concentrations of all elements, and the average concentration was closest to that of the ICP-MS measurement for $\mathrm{Ca}$, which was $11 \%$ higher in FPXRF. Similar to the ground fine fraction reject, the largest difference was for $\mathrm{V}$, where FPXRF showed $700 \%$ higher results. One reason for the differences between the results could be unburned carbon since Xing et al. (2016) found that unburned carbon in biomass ash could lead to inaccurate results for XRF, and heating at $815^{\circ} \mathrm{C}$ could improve the consistency and the reliability of ash analysis. 


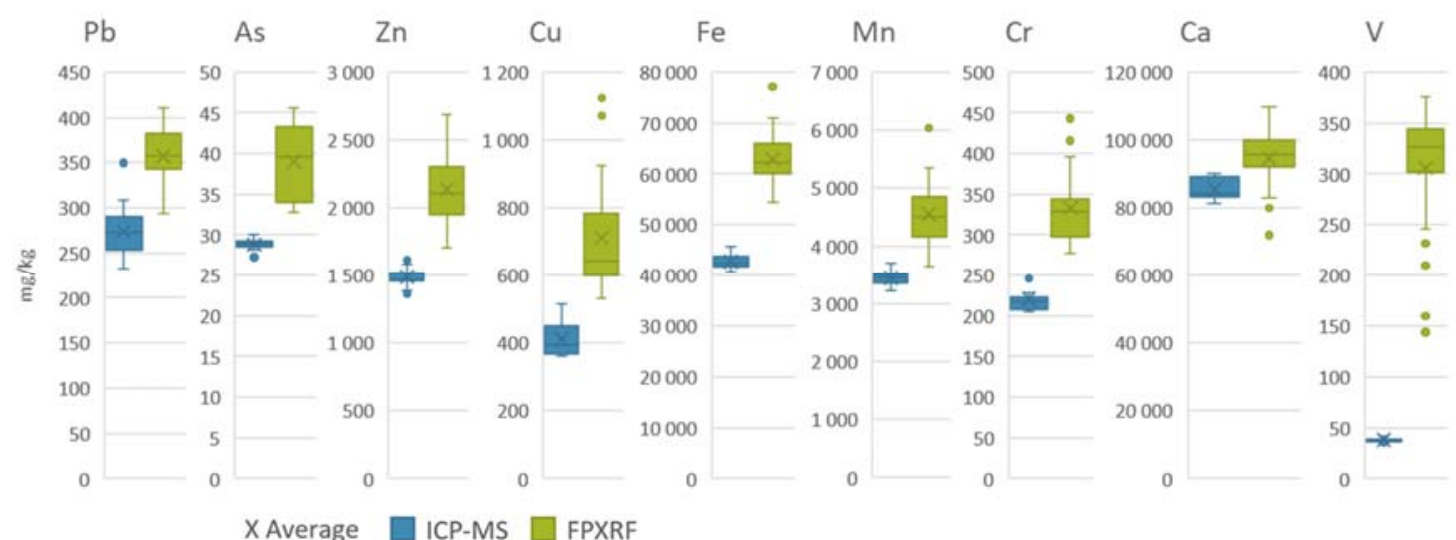

Figure 2. Box plots of ICP-MS and FPXRF measurements of ash (the dots represent outliers).

Figure 3 illustrates the box plot comparison of the results between FPXRF and ICP-MS measurements for compost. Figure 3 clearly shows that ICP-MS results in higher values than FPXRF for the majority of the elements and that the middle $50 \%$ of the data overlaps only slightly with $\mathrm{Cu}$. The differences between ICP-MS and FPXRF averages are below $10 \%$ only for $\mathrm{Fe}$ and $\mathrm{Cu}$ but above $200 \%$ for $\mathrm{V}$ and $\mathrm{Mn}$.

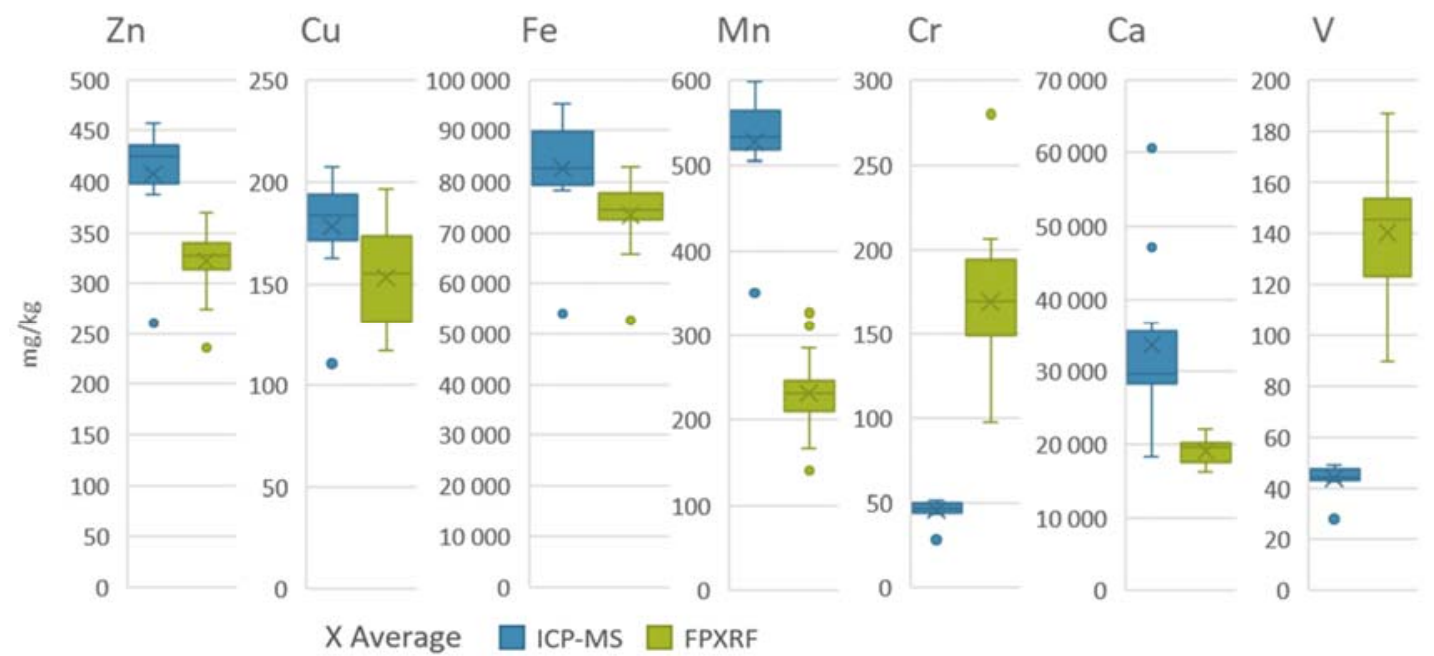

Figure 3. Box plots of ICP-MS and FPXRF measurements of compost (the dots represent outliers).

The compost measurements can be compared with those of the study conducted by McWhirt et al. (2012). They evaluated compost element concentrations by using portable X-ray fluorescence spectrometry (PXRF) and compared the results with inductively coupled plasma atomic emission spectroscopy (ICP-AES). Their results showed high RSD values, $70 \%$ and higher, for all elements when measured with PXRF, whereas this present study showed much lower RSD values, ranging from $6 \%$ to $23 \%$. The much larger RSD values obtained by McWhirt et al. (2012) could be due to their much wider base of raw materials used for compost, such as biowaste, animal manure, wood chips, and industrial sludge. In this present study, the compost consisted of biowaste, sludge, and garden waste from municipal sources. Weindorf et al. (2008) also compared XRF results with those of ICP-AES and found that XRF was useful for screening excess levels of $\mathrm{Ni}, \mathrm{Cu}, \mathrm{Zn}$, and $\mathrm{Pb}$, for example, but more accurate 
results and a larger list of elements would require the use of ICP, especially at lower concentrations.

\subsection{Limits of agreement and regression analysis}

The results of the agreement analysis by using the Bland-Altman plot analysis are shown in Table 5, and the Bland-Altman plots are illustrated in the supplementary material (Figures S2 and S3). The mean of the differences shows that on average, FPXRF obtains lower results than those of ICP-MS for $\mathrm{Ca}, \mathrm{Cr}, \mathrm{Fe}$, and $\mathrm{Cu}$ but higher results for $\mathrm{Cu}, \mathrm{Zn}$, and $\mathrm{V}$. FPXRF also obtains higher results than those of IC for $\mathrm{Cl}$. The lower and the upper LA values indicate a high range of the difference between FPXRF and ICP-MS results. The range between the lower and the higher limits is 0.98 to 15 times the range between the average minimum and maximum values measured with ICP-MS, being lowest for Ca. For example, for Ca, FPXRF can obtain $33690 \mathrm{mg} / \mathrm{kg}$ lower or $19511 \mathrm{mg} / \mathrm{kg}$ higher results, leading to a difference of $53201 \mathrm{mg} / \mathrm{kg}$, while the difference between the average minimum and maximum values measured with IPC-MS is $54106 \mathrm{mg} / \mathrm{kg}$. These findings indicate that there is not acceptable level of agreement between the measurement methods for the examined element measurements since the differences are too large.

Table 5. Results of Bland-Altman analysis of agreement between FPXRF and ICP-MS/IC (mg/kg).

\begin{tabular}{llllllll}
\hline & $\mathrm{Ca}$ & $\mathrm{Cr}$ & $\mathrm{Fe}$ & $\mathrm{Cu}$ & $\mathrm{Zn}$ & $\mathrm{V}$ & $\mathrm{Cl}$ \\
\hline Mean of difference & -7090 & -18 & -7313 & -601 & 83 & 127 & 507 \\
SD of difference & 13572 & 212 & 25697 & 1561 & 460 & 106 & 2097 \\
Limits of agreement & & & & & & & \\
Lower & -33690 & -434 & -57678 & -3660 & -820 & -81 & -3603 \\
Upper & 19511 & 397 & 43051 & 2458 & 985 & 335 & 4616 \\
\hline
\end{tabular}

Table 6 summarizes the results of the regression analysis between FPXRF and ICP-MS measurements for $\mathrm{Ca}, \mathrm{Cr}, \mathrm{Fe}, \mathrm{Cu}, \mathrm{Zn}$, and $\mathrm{V}$ and between FPXRF and $\mathrm{IC}$ for $\mathrm{Cl}$ in SRF ground fine fraction, compost, and ash samples. According to the $\mathrm{R}^{2}$ value, only $\mathrm{Ca}$ could be determined as definitive, $\mathrm{Zn}$ could be deemed quantitative, $\mathrm{Fe}$ is close to being quantitative, and the rest of the elements $(\mathrm{Cr}, \mathrm{Fe}, \mathrm{Cu}, \mathrm{V}$, and $\mathrm{Cl})$ could be categorized as only qualitative. When considering both the $\mathrm{R}^{2}$ and the RSD of the FPXRF results (Table 2), the results are similar; only Ca could be classified as definitive and $\mathrm{Zn}$ as quantitative. McWhirt et al. ( 2012) found higher $R^{2}$ values for the regression between the PXRF and the ICP-AES measurements of elemental concentrations in compost $(0.78$ to 0.92 for $\mathrm{Ca}, \mathrm{Cr}, \mathrm{Cu}, \mathrm{Fe}$, and $\mathrm{Zn})$, but the agreement between the results was not studied.

Table 6. Results of regression analysis between FPXRF and ICP-MS/IC measurements for SRF fine fraction, ash, and compost samples.

\begin{tabular}{l|lll}
\hline & \multicolumn{3}{|l}{ Regression analysis } \\
Element & $\mathrm{R}^{2}$ & Slope & y-intercept \\
\hline $\mathrm{Ca}$ & 0.95 & 2.09 & -5.28 \\
$\mathrm{Cr}$ & 0.41 & 0.34 & 1.51 \\
$\mathrm{Fe}$ & 0.69 & 0.90 & 0.39 \\
$\mathrm{Cu}$ & 0.37 & 0.55 & 1.01 \\
$\mathrm{Zn}$ & 0.88 & 1.62 & -1.89 \\
$\mathrm{~V}$ & 0.00 & -0.12 & 2.30 \\
$\mathrm{Cl}$ & 0.19 & 0.05 & 3.40 \\
\hline
\end{tabular}


The test of the agreement reveals that the results obtained by the two methods are unacceptably divergent. Additionally, regression analysis shows a linear correlation only with $\mathrm{Ca}$ and $\mathrm{Zn}$ values. This finding would indicate that a linear correction could be possible for $\mathrm{Ca}$ and $\mathrm{Zn}$ values to be used to transform FPXRF results to be comparable to ICP-MS results, but this seems impossible for the rest of the elements used in the regression analysis. The regression curves of $\mathrm{Ca}, \mathrm{Zn}$, and $\mathrm{Fe}$ are presented in the supplementary material (Figure S4).

\subsection{Limitations and benefits of FPXRF}

Both the physical and the chemical properties of the samples affect measurement accuracy. Based on the RSD values, the FPXRF method can be best applied to waste samples such as ash and compost because they are relatively homogeneous, dry, and have relatively uniform and small particle sizes. This method is not as suitable for biowaste because it is very heterogeneous and has a variable particle size. For the same reasons, the method is also inappropriate for coarse SRF fine fraction reject. FPXRF can be used for qualitative measurements of different types of samples. However, quantitative measurements are more challenging because the number of factors can affect the measurement results (Hou et al., 2004). The sample's moisture content, chemical and physical matrix effects (e.g., interelement effects, particle size, and homogeneity), instrument resolution, and inconsistent positioning of samples are some examples of these factors (Gutiérrez-Ginés et al., 2013; Hou et al., 2004; Kalnicky and Singhvi, 2001). The reliability and the accuracy of the FPXRF measurement depend on the time used for a single measurement, calibration and reference standards, and pretreatment (e.g., drying, sieving, and homogenization) (Hou et al., 2004; Kalnicky and Singhvi, 2001). In addition, according to the results by Ravansari and Lemke (2018), the organic content of the sample has also elementally dependent response on the FPXRF results.

The FPXRF analysis could provide an alternative analysis method from the green analytical chemistry point of view (Armenta et al., 2008). The need for toxic reagents would be reduced if for example ICP-MS measurements could be reduced or replaced by FPXRF. The device used for the pretreatment of samples for ICP-MS needs strong acids while ICP-MS requires argon in the measurements. These both could be reduced if FPXRF could replace some ICPMS measurements. Gałuszka et al. (2013) proposed 12 principles of green analytical chemistry and FPXRF could fulfill at least following ones: avoiding analytical waste, minimizing the use of energy and eliminating toxic reagents.

\section{Conclusions}

The standard laboratory methods provide accurate results for waste measurements, but these methods can be expensive and time-consuming. However, to determine more accurately those portions of waste materials that are or could be suitable for utilization, faster real-time measurement methods are needed. Portable spectrometric measurement devices could meet the demand by allowing a large number of measurements to produce data about the variations and the averages of the properties. However, it should be borne in mind that the sample moisture content, particle size, homogeneity and organic content of sample affect to the 
FPXRF measurement results. According to the results obtained in the present study, FPXRF obtains the lowest RSD values for ash samples and the highest values for the coarse fine fraction reject. The variations in element concentrations are lowest for ash, both with FPXRF and ICP-MS. The closest results between the two methods are for $\mathrm{Ca}$.

The analysis of the LA between FPXRF and ICP-MS shows that the upper and the lower limits for most of the elements are divergent and that FPXRF is mainly suitable for qualitative assessment. The regression analysis indicates a linear correlation between FPXRF and ICPMS results for $\mathrm{Ca}$ and $\mathrm{Zn}$ values, which could be used in making linear corrections for FPXRF results. Keeping the limitations in mind, FPXRF could be used for qualitative analysis in waste treatment processes, such as first quality control of waste material in waste treatment plants and landfills. In this kind of first quality control, lower cost, speed, and portability could be more important than losses in accuracy. For example, the materials suitable for further utilization (with detected concentrations well below the limits) could be directed to a different pile, separate from the materials requiring further analysis (with concentrations close to the limits). Although the FPXRF measurements could not fully replace the traditional laboratory analysis, they could reduce the number of the latter.

\section{Acknowledgments}

This study was conducted in the Material value chains (ARVI) program (2014-2016). Funding for the program was received from Tekes (the Finnish Funding Agency for Innovation), industry and research institutes.

\section{References}

333/221. Government Decree on landfills (in Finnish).

Armenta, S., Garrigues, S., de la Guardia, M., 2008. Green Analytical Chemistry. TrAC Trends in Analytical Chemistry 27, 497-511. https://doi.org/10.1016/j.trac.2008.05.003

Block, C.N., Shibata, T., Solo-Gabriele, H.M., Townsend, T.G., 2007. Use of handheld X-ray fluorescence spectrometry units for identification of arsenic in treated wood. Environmental Pollution 148, 627-633. https://doi.org/10.1016/j.envpol.2006.11.013

Burlakovs, J., Kaczala, F., Orupõld, K., Bhatnagar, A., Vincevica-Gaile, Z., Rudovica, V., Kriipsalu, M., Hogland, M., Stapkevica, M., Hogland, W., Klavins, M., 2015. Fieldportable X-ray fluorescence spectrometry as rapid measurement tool for landfill mining operations: comparison of field data vs. laboratory analysis. International Journal of Environmental Analytical Chemistry 95, 609-617. https://doi.org/10.1080/03067319.2015.1036865

EPA, 2007. Method 6200 - Field Portable X-Ray Fluorescence Spectrometry for the Determination of Elemental Concentrations in Soil and Sediment, Method 6200. https://doi.org/10.1017/CBO9781107415324.004

Gałuszka, A., Migaszewski, Z., Namieśnik, J., 2013. The 12 principles of green analytical chemistry and the SIGNIFICANCE mnemonic of green analytical practices. TrAC Trends in Analytical Chemistry 50, 78-84. https://doi.org/10.1016/j.trac.2013.04.010

Gałuszka, A., Migaszewski, Z.M., Namieśnik, J., 2015. Moving your laboratories to the field 
- Advantages and limitations of the use of field portable instruments in environmental sample analysis. Environmental Research 140, 593-603.

https://doi.org/10.1016/J.ENVRES.2015.05.017

Gutiérrez-Ginés, M.J., Pastor, J., Hernández, A.J., 2013. Assessment of field portable X-ray fluorescence spectrometry for the in situ determination of heavy metals in soils and plants. Environmental science. Processes \& impacts 15, 1545-52.

https://doi.org/10.1039/c3em00078h

Hasan, A.R., Solo-Gabriele, H., Townsend, T., 2011. Online sorting of recovered wood waste by automated XRF-technology: Part II. Sorting efficiencies. Waste Management 31, 695-704. https://doi.org/10.1016/j.wasman.2010.10.024

Havukainen, J., Nguyen, M.T., Hermann, L., Horttanainen, M., Mikkilä, M., Deviatkin, I., Linnanen, L., 2016. Potential of phosphorus recovery from sewage sludge and manure ash by thermochemical treatment. Waste Management 49, 221-229. https://doi.org/10.1016/j.wasman.2016.01.020

Hou, X., He, Y., Jones, B.T., 2004. Recent advances in portable X-Ray Fluorescence Spectrometry. Applied Spectroscopy Reviews 39, 1-25. https://doi.org/10.1081/ASR120028867

Kalnicky, D.J., Singhvi, R., 2001. Field Portable XRF analysis of environmental samples. Journal of Hazardous Materials 83, 93-122.

Kilbride, C., Poole, J., Hutchings, T.R., 2006. A comparison of Cu, Pb, As, Cd, Zn, Fe, Ni and $\mathrm{Mn}$ determined by acid extraction/ICP-OES and ex situ field portable X-ray fluorescence analyses. Environmental Pollution 143, 16-23. https://doi.org/10.1016/j.envpol.2005.11.013

Martin Bland, J., Altman, D.G., 1986. Statistical methods for assessing agreement between two methods of clinical measurement. The Lancet 327, 307-310. https://doi.org/10.1016/S0140-6736(86)90837-8

McWhirt, A., Weindorf, D.C., Zhu, Y., 2012. Rapid Analysis of Elemental Concentrations in Compost Via Portable X-ray Fluorescence Spectrometry. Compost Science \& Utilization 20, 185-193. https://doi.org/10.1080/1065657X.2012.10737045

Miller, C.L., Watson, D.B., Lester, B.P., Lowe, K.A., Pierce, E.M., Liang, L., 2013. Characterization of soils from an industrial complex contaminated with elemental mercury. Environmental Research 125, 20-29. https://doi.org/10.1016/J.ENVRES.2013.03.013

Radu, T., Diamond, D., 2009. Comparison of soil pollution concentrations determined using AAS and portable XRF techniques. Journal of Hazardous Materials 171, 1168-1171. https://doi.org/10.1016/j.jhazmat.2009.06.062

Ranganathan, P., Pramesh, C.S., Aggarwal, R., 2017. Common pitfalls in statistical analysis: Measures of agreement. Perspectives in clinical research 8, 187-191. https://doi.org/10.4103/picr.PICR_123_17

Ravansari, R., Lemke, L.D., 2018. Portable X-ray fluorescence trace metal measurement in organic rich soils: pXRF response as a function of organic matter fraction. Geoderma 319, 175-184. https://doi.org/10.1016/J.GEODERMA.2018.01.011

Sterling, D.A., Lewis, R.D., Luke, D.A., Shadel, B.N., 2000. A Portable X-Ray Fluorescence Instrument for Analyzing Dust Wipe Samples for Lead: Evaluation with Field Samples. 
Environmental Research 83, 174-179. https://doi.org/10.1006/ENRS.2000.4058

Weindorf, D.C., Sarkar, R., Dia, M., Wang, H., Chang, Q., Haggard, B., McWhirt, A., Wooten, A., 2008. Correlation of X-ray Fluorescence Spectrometry And Inductively Coupled Plasma Atomic Emission Spectroscopy for Elemental Determination In Composted Products. Compost Science \& Utilization 16, 79-82.

https://doi.org/10.1080/1065657X.2008.10702361

Weindorf, D.C., Zhu, Y., Chakraborty, S., Bakr, N., Huang, B., 2012. Use of portable X-ray fluorescence spectrometry for environmental quality assessment of peri-urban agriculture. Environmental Monitoring and Assessment 184, 217-227.

https://doi.org/10.1007/s10661-011-1961-6

Xing, P., Mason, P.E., Chilton, S., Lloyd, S., Jones, J.M., Williams, A., Nimmo, W., Pourkashanian, M., 2016. A comparative assessment of biomass ash preparation methods using X-ray fluorescence and wet chemical analysis. Fuel 182, 161-165. https://doi.org/10.1016/J.FUEL.2016.05.081 